\title{
A General Review of the Translation and Publication of Lin Yutang's English Works in China
}

\author{
Xiuyan Zhang
}

are also pointed out.

\begin{abstract}
This paper aims to make a general introduction of the translation and publication of Lin Yutang's English works in China. Lin Yutang was a famous writer, who wrote over 30 English works. His works were very popular worldwide from 1930 s to 1960s. Many of them were translated into many other languages and published in different countries. In Lin Yutang's motherland, the translation of these works was mainly carried out in two periods: the first period was from 1930s to 1940s, that's shortly after the publication of the original works; the second period was from 1970s to 1980s after Lin Yutang returned and settled in Taiwan.
\end{abstract}

Index Terms - China, Lin Yutang, publication, translation.

\section{INTRODUCTION}

Lin Yutang was an important writer in the last century, who wrote over 30 English works and had them published mostly first in America. These works intended to introduce Chinese culture to the western world and did it very successfully. Many of Lin's works were translated into different languages and published all over the world. In China, people also have to rely on translated works, since most readers don't read English. Some of Lin's English works were translated and published in China shortly after the publication of the original works, but most of them were translated in 1970s.

Today, Lin's works are still very popular in Chinese book market, especially in Mainland China, some of them are best-sellers. Readers and scholars are very interested in Lin's works. Readers read the translated versions and most scholars had to base their study on the translated versions. But many readers don't know that they are reading translated versions, assuming that they are reading the original works. Lin Yutang was a Chinese, so readers take it for granted that he wrote in Chinese.

In recent years, there is more and more research about Lin Yutang. The research is carried out from different perspectives, such as the writing style of Lin Yutang, the characters in Lin's works, the relation between Lin Yutang and other people, the translation of Lin's works, etc,. The translation study mainly focus on Lin's translation strategy or the strategies translators used in translating Lin's English works into Chinese. But there is little study on the translators and the publication of Lin's works. This paper intends to make a general review of the works translated and their translators, some problems in the publication of Lin's works

Manuscript received September 1, 2016; revised November 23, 2016. This work was supported in part by Fujian Social Science Association under Grant FJ2015C201.

Xiuyan Zhang is with Foreign Language Institute, Quanzhou Normal University, Quanzhou, Fujian, China (e-mail: xiuyan160@163.com).

\section{AN INTRODUCTION OF LIN YUTANG AND HIS ENGLISH WORKS}

Lin Yutang was born in 1895 to a Christian family in a small village in south China. His father, Lin Zhicheng, was a priest. So Lin Yutang received education from church-funded schools from primary school to university. In 1912, when he was 17, Lin went to Shanghai and entered Saint John's University, which was famous for its English teaching. Lin learnt English and a lot about western culture in the university. After graduation, he went to Qinghua Universtiy in Beijing and worked there as a teacher. Several years later, he got the chance to go abroad and receive further education. He received his master's degree from Harvard University, and $\mathrm{PhD}$ in linguistic from Leipzig University. The education abroad improved his mastery of English and deepened his understanding of western culture, which laid a solid foundation for his future writing.

In 1935, Lin published his first English work My Country and My People in America. Pearl S. Buck, who encouraged Lin to write this book, wrote an introduction for the book, in which she praised the book as "the truest, the most profound, the most complete, the most important book yet written about China" [1]. My Country and My People quickly gained great popularity in America and Lin Yutang became a famous writer almost overnight. He was surprised and greatly inspired. At the same time, readers wanted to know more about Chinese culture. Thus under the suggestion of the publisher, Lin wrote another book The Importance of Living and had it published in 1937 by the John Day Company. Again, this book became a great success; it became the top-seller in US book market. In the following 30 years, Lin spent most of his time in writing or translating books about China. He was a prolific writer, writing over 30 books in English. Besides the two mentioned above, his other main works include: The Wisdom of Confucius (1938), Moment in Peking (1938), A Leaf in the Storm (1938), Between Tears \& Laughter (1943), The Gay Genius: The Life and Times of Su Tungpo (1947), The Wisdom of Laotse (1948), The Vermilion Gate (1953), Lady Wu (1955), The Red Peony (1961), etc.

With these works, Lin successfully introduced Chinese culture to the western world; this was one of his greatest contributions.

III. The Translation OF Lin Yutang's ENGLish Works IN CHINA

\section{A. Works Translated}

Lin Yutang wrote over 30 English works from 1930s to 
1960s. Many of these works were popular in the western world and were translated into many other languages.

In China, many of Lin's works were also translated. The translation of these works was carried out in two periods: the first period is from 1930s to1940s, the second period from 1970s-1980s.

In the first period, the translation was mainly carried out in Mainland China and focused on three works: My Country and My People, The Importance of Living and Moment in Peking.

My Country and My People was published in 1935. After its publication, Lin invited his friend Huang Jiade to translate it into Chinese. So in 1936, the Chinese version of My Country and My People (Wu Guo Wu Min) was published. This version was very popular at that time. At the same time, there were several abridged versions in the book market. In 1938, another version translated by Zheng Tuo was published. It circulated for only several years, and was not published any more.

The Importance of Living was published in 1937, and became one of the most popular works among Lin's all works. When Huang Jiade read this book in Shanghai, he felt that it was a very good book and intended to translate it into Chinese. So he wrote a letter to Lin, who was living in America at that time, to ask for the permission to translate The Importance of Living. Lin agreed and helped Huang in the process of translation. Huang Jiade began to translate in 1938 and had it serialized in the Journal West Wind, which was co-founded by Lin Yutang and Huang Jiade. He published one or two parts of each chapter in every issue of West Wind, so the pace of translation was quite slow, and the serialization lasted almost three years until 1941. In 1941, West Wind Publishing House decided to publish the whole book, because "during the process of the serialization, readers frequently wrote to ask for early publication of the complete book"[2], so the publishing house decided to stop the serialization after they finished the publication of chapter ten. This was one of the reasons to stop the serialization, but there was a more important one. At the end of 1940, World Culture Publishing House published a complete Chinese version of The Importance of Living. It was then the only complete version, so readers were naturally attracted by it and thus taken away from West Wind. This made the West Wind Publishing House suffers a big lost. In order to minimize the lost, they had to issue the complete version as soon as possible. Although Huang Jiade was the first person to translate The Importance of Living, his complete translation was not available until 1941.

Moment in Peking was Lin's first English novel, it was published in 1939. For the translation of this novel, Lin had a plan even before the publication of the novel. He wrote to his friend Yu Dafu, a famous writer and poet, and asked him to translate the novel, because he believed Yu was the perfect translator for the novel, for on the one hand, Yu was very fluent in English, on the other hand, he knew very well the features of Beijing dialect. Yu Dafu accepted the invitation. Lin was very pleased and sent him a copy of the novel with a lot of notes, indicating the source of allusions and quotes and the name of the characters and places, hoping $\mathrm{Yu}$ could quickly start the translation. But $\mathrm{Yu}$ was very busy at that time, so the translation delayed again and again. Until 1941, $\mathrm{Yu}$ finally began to translate and the translation was serialized in Overseas Chinese Weekly in Singapore. Unfortunately, the Overseas Chinese Weekly ceased to publish because of the war, so the translation also stopped. What's more, the part that had been translated were not reserved for Overseas Chinese Weekly "was supportive of the anti-Japanese war, so those stored in public organizations were destroyed, those saved by common readers were also ruined [3]". Meanwhile, the first complete Chinese version Jing Hua Yan Yun was published in 1940, co-translated by Zheng Tuo and Ying Yuanjie. Lin read the version and wrote an article to comment on the translation in 1941. In that article, he said, "in general, the translation was not very bad judged by the standard of modern translation; but there were some unnatural sentences [4]." From the comments in that article, we can see that Lin was not very satisfied with this version, especially the Europeanized Chinese. He cited many examples from the translation to show the awkwardness of the language. This version was circulated widely in 1940s.

The second period of translation was from 1970s to 1980s, mainly carried out in Taiwan. In this period, over 10 books were translated and many translators were involved.

Lin Yutang stayed overseas for about 30 years, but decided to return to China in 1960s. In 1966, Lin returned to Taiwan and settled there. This caused a "Lin Yutang Hot" in Taiwan. Lin was very famous worldwide, so readers in Taiwan were eager to know him and to read his works. But until then only several Chinese versions of his works, such as My Country and My People, The Importance of Living and Moment in Peking were available. So in 1970s, many of Lin's English works were translated and published.

In 1970s, Yuanjing Publishing House and Dehua Publishing House were the two publishing houses that published a lot of Lin's works. Many of these works were also published in Hong Kong. It is interesting to notice that these two publishing houses published almost the same books, but used different versions. Yuanjing mainly used versions translated by Song Biyun, whereas Dehua mostly used those translated by Zhang Zhenyu. It looks like that the two publishing houses were having a competition. In 1975, Looking Beyond translated by Song Biyun, and the other version translated by Zheng Qiushui was published by Yuanjing. In 1976, A Leaf in the Storm, The Vermilion Gate, Chinatown Family, Juniper Loa, all translated by Song Biyun, were published by Yuanjing. In the same year, Lady $\mathrm{Wu}$ translated by Zhang Zhenyu was published by Dehua Publishing House. In 1977, The Gay Genius: The Life and Times of Su Tungpo translated by Song Biyun, Moment in Peking, Red Peony translated by Zhang Zhengyu, Chinatwon Family translated by Tang Qiang was published. Until the end of 1970s, over ten of Lin's English works were translated and several of them had over two versions, such as Red Peony, Lady Wu, Looking Beyond, Chinatown Family, etc. In 1984, Jinlan Culture Publishing House in Taiwan published a collection of Lin's works; included 35 books in the collection, many of them were translated in 1970s.

In 1980s, the translation of Lin's works was also carried out in Mainland China. In 1988, Hao Zhidong and Shen Yihong co-translated My Country and My People. At that 
time, in Mainland China, there were few Lin's works published. So Hao and Shen decided to translate this book. Hao was responsible for preface, introduction and chapters one to six; Shen translated chapters seven to ten. This is the first complete Chinese version of My Country and My People, for the previous versions omitted chapter ten which might cause controversies. What's more, they added some notes, the translators' words and index to the translation, which helped readers to understand. Another important thing is that the translators decided to change the title (Wu Guo Wu Min) translated by Huang Jiade to a totally new title Zhong Guo Ren (Chinese People). This version was then published in 1988 by Zhejiang People's Fine Arts Publishing House. It was popular for some years, but was not widely circulated and was not published anymore after 2009. An important reason is the change of the title. In China, readers know that Lin Yutang wrote $\mathrm{Wu}$ Guo $\mathrm{Wu}$ Min (the title translated by Huang Jiade), when they want to read My Country and My People, they naturally choose Huang's version. Many readers don't know that Zhoug Guo Ren and Wu Guo Wu Min are the different translations of the same book.

There is another book translated in Mainland China in 1980s, which is Moment in Peking. When the novel was published, Lin Yutang invited his friend Yu Dafu to translate the novel. Yu agreed and translated part of it to Chinese, but was not able to continue. Over forty years later, Yu Dafu's son Yu Fei decided to fulfill the task that his father failed. So he began to collect information and started to translate in 1986. At the end of 1990, he finished the translation. Yu Fei decided to abandon the title Jing Hua Yan Yun, which had been used for a long time. Instead he used another title Sun Xi Jing Hua for his translation, which was proposed by Lin Yutang in one of his letters to Yu Dafu. This version was published by Hunan Literature and Art Publishing House in 1991 and was reprinted in 1994. In 1996, Writers Publishing House also published this book. Afterwards, it was not published anymore.

\section{B. Main Translators}

Most of Lin Yutang's English works were translated into Chinese, mostly by other translators, several ones by Lin himself. Although many readers are still reading Lin's works, few of them know who translated the works; some of them even are not aware that they are reading translated works. There are many translators involved in the translation of Lin's English works. Some of them translated only one or two books, some others translated many.

Huang Jiade (1908-1992) was the first translator of Lin Yutang's English works. He was born in Jinjiang, Fujian Province. Like Lin Yutang, he was also born to a Christian family. In 1925, he was accepted by Fukien Christian University, majored in Medicine. But he was interested in Chinese and western literature, so in 1928 he went to Saint's John's University and changed his major to English. After graduation, he stayed in Saint John's University and worked as a teacher, teaching Chinese, translation and other courses. From 1936, he began to translate Lin Yutang's English works. The first one was My Country and My People. Later, he also translated Lin's other works, including: The Importance of Reading, The Wisdom of Confucius and The Wisdom of
Laotse. His version of My Country and My People was widely published in Taiwan, Hong Kong and Mainland China. In Mainland China book market, it is now the only version that is still circulating. The Wisdom of Confucius and The Wisdom of Laotse are also still published along with other versions.

Although Huang Jiade was the first one to translate The Importance of Living, his version was not published after 1950s in Mainland China. The version that is widely used nowadays was translated by Yue $\mathrm{Yu}$ in 1940. One of the important reasons is because of Lin Yutang's comment on this translation. Although Lin categorized Huang's translation as the one "without problem", he made no other comments on it. But he commented Yue Yu's version, by saying "this translation is pretty good, the quotes were translated correctly" [5]. It is this comment that helped Yue Yu's version to become the most widely circulated version of The Importance Reading. This is quite unfair to Huang Jiade, because Yue's translation copied some parts from Huang's version, especially the first several chapters.

Among the translators of Lin's English works, Zhang Zhenyu and Song Biyun were the most prolific ones; both translated about 10 of Lin's books.

Zhang Zhenyu (1916-1995) was born to a rich family in Hebin Province, in northern part of China. When he was 12, he moved to Peking with his family. He was interested in classical Chinese, poetry, Chinese opera and novel. When he was in senior high school, he began to read Lin Yutang's Chinese articles which were published in famous journals such as West Wind, Lun Yu and so on. After graduating from middle school, he was accepted by $\mathrm{Fu}$ Jen Catholic University in Peking and majored in Western language and literature. In 1951, he went to Taiwan and stayed until the end of his life. He taught first in Chinese Culture University and then in Taiwan University. In 1970s, he translated 10 of Lin's English works, including: The Importance of Living, Moment in Peiking, The Gay Genius: The Life and Times of Su Tungpo, Lady Wu, Red Peony, Famous Chinese Short Stories, The Wisdom of Confucius, The Unexpected Island, A Leaf in the Storm and The eighty Autobiography. These works were translated and first published in Taiwan, and later entered Hong Kong and Mainland China book market. Nowadays, except The Importance of Living, all the works translated by Zhang Zhengyu are still published and most of them are very popular.

Song Biyun was a translator from Taiwan, she also translated about 10 of Lin's English works, including: Red Peony, The Gay Genius: The Life and Times of Su Tungpo, A Leaf in the Storm, Chinatown Family, Juniper Loa, Lady Wu, Looking Beyond, The Eighty Autobiography and The Vermilion Gate. In Mainland China, there is little research about her, and little information could be found.

Besides the above mentioned translators, there are some other translators who translated only one or two of Lin's works. They are Zheng Qiushui who translated A Leaf in the Storm and Looking Beyond; Wang Lingling who translated The Unexpected Island and The Flight of the Innocents; Tang Qiang who translated Chinatown Family; Xie Chaoyun who translated Juniper Loa, Hao Zhidong and Shen Yihong who translated My Country and My People and Yu Fei who 
translated Moment in Peking. These are just some of them; there are many more translators who are ignored.

\section{The Publication of Lin Yutang’s Works}

\section{A. The Publication of the Chinese Versions of Lin's English Works}

From 1930s, the translated works of Lin's English works were published in Mainland China, Taiwan and Hong Kong. In Mainland China, the publication ceased from 1950s to the end of 1970s. But in Taiwan and Hong Kong, Lin's works were always published, especially in Taiwan in 1970s to 1980s. From 1980s, Lin's works returned to Mainland China book market and continued to be popular until today.

From 1950s to the end of 1970s, there were no Lin's works published in Mainland China, either Chinese or English works. Lin's works were completed prohibited mainly due to political reasons. Lin sympathizes with Chinese Nationalist Party or Kuomintang, which was forced to withdraw from Mainland China to Taiwan in 1949 because of the conflicts between the two parities. So from the end of 1940s to the end of 1970s, books supportive of Kuomintang were not published in Mainland China. At the end of 1970s, China adopted a reform and opening up policy, so Lin's works gradually returned to Mainland China. In 1980, Shanghai Bookstore published a collection of the Chinese versions of Lin Yutang's novels, including Lady Wu and The Vermilion Gate. This was the beginning of the return of Lin's works into the mainland. In 1981, Shidai Art and Literature Publishing House also published a collection of Lin's works, including: The Gay Genius: The Life and Times of Su Tungpo. In 1981, Writers Publishing House published a collection of Lin' works. The publication of these works showed that from 1980s, Lin's works were not prohibited anymore in Mainland China, although there were still few of them published.

From the end of 1980s, more and more of Lin's works were published and more publishing houses were involved. My Country and My People, The Importance of Living, Moment in Peking, Red Peony, Lady Wu, Juniper Loa and many other works were published. Many publishing houses began to publish complete collections of Lin's works, including some of Lin's Chinese works and Chinese versions of his English works. Most of these Chinese translations were introduced to the mainland from Taiwan. Only three of them were translated by translators in the mainland, namely: My Country and My People by Huang Jiade, Zhong Guo Ren(the other version of My Country and My People) by Shen Zhidong and Shen Yihong and The Importance of Living by Yue Yu.

\section{B. Problems in the Publication}

In recent years, Lin's works are still popular. More and more publishing houses are eager to publish Lin's works. And there are more and more scholars involved in Lin Yutang study. But there are some problems in the publication of Lin's works, which were always ignored.

There are mainly three problems in the publication of Lin's English works. The first problem is that the translated versions used nowadays are very old, some were translated in 1930 s, and some were in 1970 s, the newest ones in 1980s.
Take My Country and My People as an example. There are two popular Chinese versions: Wu Guo Wu Min translated by Huang Jiade in 1936 and Zhong Guo Ren translated by Shen Zhidong and Shen Yihong in 1988. But since 2010, Zhong Guo Ren was not published anymore, so the only version available in Mainland China book market is Huang Jiade's version. This version is so old that it does not suit modern readers' taste. The language used in this version mixed classical Chinese and modern Chinese, which are very different. Most modern readers can not completely understand classical Chinese, because it was gradually replaced by modern Chinese which is simpler and more direct, since the early 20th century. For modern readers, classical Chinese looks very old-fashioned and abstruse.

Another example is The Importance of Living, which is one of the most popular books written by Lin Yutang. From the online bookseller dangdang.com, we find that the Chinese version available is the one translated by $\mathrm{Yue} \mathrm{Yu}$ in 1940. The Wisdom of Laoste has two Chinese versions: one was translated by Huang Jiade around 1940, the other one translated by Zhang Zhenyu in 1970s. The situation is similar for other works.

These old versions of translation sometimes cause misunderstanding or confusion. Take The Importance of Living as an example. Yue Yu's version of The Importance of Living is now the only Chinese version circulating in Mainland China. When the readers read the heading of part five, chapter nine, they may not understand. Yue translated the heading "On Smoke and Incense" into "Danbagu $\mathrm{He}$ Xiang". In this translation, "smoke" was translated into "Danbagu", which sounds like a kind of mushroom and can not be understood by modern readers. We have to read the contents in this part to know what "Danbagu" is. Lin wrote that "...there is comparatively little praise of tobacco in Chinese literature...[6]" On second thoughts, we find to our surprise that "Danbagu" is "tobacco". In 1940s, it was common to use transliteration to translate foreign words. Typical examples are the translation of democracy and science, which are transliterated into "De Xian Sheng" and "Sai Xian Sheng". But, these translations are already abandoned for a long time. So modern readers do not understand what "Danbagu" is. When Yue Yu used transliteration to translate "smoke" or "tobacco", the readers of 1940s completely understand. But for modern readers, this only causes confusion.

To sum up, the Chinese versions of Lin's English works were too old to meet modern readers' demand. Some new translations are needed.

The other problem is about the quality of the translated works. Although readers and scholars read Lin's works, most of them read the translated version instead of the original because of the barrier of different languages. So, common readers can not tell whether the works are well or poorly translated. And there is little study about the quality of the translated works of Lin. When we read both the Chinese versions and the English versions of Lin's works together, we can find that there are actually many translation mistakes in many of the translated woks.

Take Moment in Peking as an example. The version that is widely used in Taiwan, Hong Kong and Mainland China is 
the one translated by Zhang Zhen Yu in 1977. It is Lin's first English novel and the most popular one. In 1988, it was adapted into a television drama in Taiwan. The popularity of the television drama attracted many people to read the novel. In 2005, it was again adapted to a television drama, this time in Mainland China. The television drama soon got very popular and it boosted the sales of the novel. All publishers in Taiwan and Mainland China use Zhang Zheyu's version. Readers and scholars like the version and think highly of it. But few readers or scholars noticed that there are actually many mistakes in this translation. There are mistakes, such as the mistake translation of numbers, the confusion of characters, the use of wrong words and misunderstanding of the whole sentence [7]. For example, when Mr. Yao's family left Beijing, heading for the south to avoid the coming war, they got mule carts and intended to go straight south to Tehchow, "the first city in Shantung, an eight- or nine-day journey, they would then be safe" [8]. Zhang Zhenyu translated "an eight- or nine-day journey" to "about eighty or ninety $\mathrm{Li}$ (Chinese unit of distance, one $\mathrm{Li}$ equals 500 meters)". This was wrong, because the distance from Beijing to Tehchow is over 500 kilometers. There are many other similar examples in Zhang Zhenyu's translation. The translation mistakes not only exist in Moment in Peking. Other works also have some translation mistakes.

In The Importance of Living, there is an sentence "We had not seen each other for three years"[9], Yue translated "three years" into "san shi nian"(thirty years). In another sentence "we hear the boatmen tell us stories about the girlhood of the Queen", he translated "the Queen" into "a girl”. But in this context, "the Queen" referred to Empress Dowager Cixi, not just any girl. Whereas, in Huang Jiade's version, the translation was correct.

The third problem is the omission of the translators. Since Lin Yutang was very famous, when the publishing houses published Lin's works, they tried to emphasize the identification of the author. Since China is not very strict with copyright law, many publishing houses simply omit any information about the translator. They printed on the covers information such as "Lin Yutang's master piece", "written by Lin Yutang, master of Chinese culture", "world famous writer" and so on, but shows no any information of the translators. This omission causes some misunderstanding to the readers. As Lin was a Chinese writer, some readers don't know his experience, so they take it for granted that Lin wrote his works in Chinese. So some readers don't know that they are reading the translated works, instead of Lin's original works. A typical example is Moment in Peking. This novel becomes very popular, especially after the 2005 TV series in Mainland China. Many readers begin to read the novel after they watched the TV series. They love the novel, but few of them know there is an original work and what they are reading is translated text.

It is actually not difficult to solve the problem. What the publishing houses should do is simply to add the information about the translator. For example, they should print the translators' names beside the author's name, by saying “written by Lin Yutang, translated by ***(the translator's name)". This would be very clear for the readers. Besides, publishers can add some other information. In some translated works, the translators wrote preface to the work. This information is very useful to the readers. It will help them to know how the original work was written and how it was translated, thus misunderstandings could be avoided.

These three problems in the Chinese versions of Lin's English works influence the quality of the works. But there are few attention paid to the problems in China. Some scholars in China Mainland, such as Wu Huijian, proposed that the retranslation of Lin's English works is very necessary to ensure a high standard Lin Yutang study [10]. But there is still little study on this topic.

\section{CONCLUSION}

In China, there are many researches about Lin Yutang. But there is little research about the translation quality of Lin's works and the problems in the publication of the works. It should be noted that this study concentrate on the publication of Lin's works in China Mainland. So there are a lot research could be done about the translation and publication of Lin's works in Taiwan, Hong Kong and Macau.

\section{REFERENCES}

[1] Y. T. Lin, My Country and My People, Beijing: Foreign Language Teaching and Research Press, Introduction, 2000.

[2] J. D. Huang, "The translator's preface to the importance of living," West Wind Monthly, vol. 55, pp. 83-84, 1941.

[3] F. Yu, Sun Xi Jing Hua, Changsha: Hunan Literature and Art Publishing House, pp. 778, 1991

[4] Fei. Yu, Sun Xi Jing Hua, Changsha: Hunan Literature and Art Publishing House, pp. 790, 1991.

[5] Y. T. Lin, Talking About Everything Under the Sun: Article Collection, Changchun: Northeast Normal University Press, pp. 504-509, 1995.

[6] Y. T. Lin, The Importance of Living, Beijing: Foreign Language Teaching and Research Press, pp. 251, 2009.

[7] X. Y. Zhang, "On the translation mistakes of the Chinese version of moment in peking," Journal of Fuqing Branch of Fujian Normal University, vol. 102, pp. 56-61, 2010.

[8] Y. T. Lin, Moment in Peking, Beijing: Foreign Language Teaching and Research Press, pp.10, 1999.

[9] Y. T. Lin, The Importance of Living, Beijing: Foreign Language Teaching and Research Press, pp. 250, 2009.

[10] H. J. Wu, "Retranslating Lin Yutang's English works: a Discussion based on my country and my peope," Academics, vol. 6, pp. 194-199, 2008.

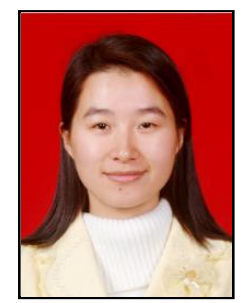

Xiuyan Zhang was born in Fujian province, China, July, 1980. She received her bachelor of arts in English language and literature from Fujian Normal University, Fuzhou since 2002-2005. She major field of study are literature transltion.

She works in foreign language institute at the Quanzhou Normal University since August, 2005. She previous publications include: 1). "The translation and reception of moment in Peking in China," Journal of Beijing International Studies University, vol. 36, pp. 56-60, 2014. 2). "On the translation mistakes of the Chinese version of moment in Peking," Journal of Fuqing Branch of Fujian Normal University, vol. 102, pp. 56-61, 2010. 3)." Lin Yutang's translation of Chinese cultural words in quiet dream shadows," Journal of Quanzhou Normal University, vol. 27, pp. 118-'23, 2009. Her current research interest is the translation study of Lin Yutang's English works. 